\title{
MANIFESTAÇÕES PATOLÓGICAS EM EDIFICAÇÕES MODERNISTAS: AS LANCHONETES DO PARQUE HISTÓRICO NACIONAL DOS GUARARAPES
}

\author{
OLIVEIRA DOS SANTOS, JÚLIA \\ Graduanda em Arquitetura e Urbanismo \\ Faculdade de Ciências Humanas ESUDA \\ Pernambuco; Brasil \\ julia_oliveiras@hotmail.com
}

\author{
EDUARDA ALVES DE BARROS, KAMYLA \\ Graduanda em Arquitetura e Urbanismo \\ Faculdade de Ciências Humanas ESUDA \\ Pernambuco; Brasil \\ eduardaabarros2@gmail.com
}

\author{
DE ARIMATÉA ROCHA, EUDES \\ Engenheiro Civil Pós Graduado em Inspeção, \\ Manutenção e Recuperação em Estruturas (UPE-Poli)/ \\ Mestre em Engenharia de Construção Civil (UPE-Poli)/ \\ Doutorando em Engenharia Civil (UFPE)/Professor na \\ Faculdade de Ciências Humanas ESUDA \\ Pernambuco; Brasil \\ eu_des@hotmail.com
}

\section{RESUMO}

Cada vez mais as edificações modernistas construídas em concreto armado estão se enquadrando como históricas. E por este motivo, é necessário elaborar processos de preservação em edificações históricas em que os arquitetos e urbanistas estejam envolvidos nas etapas de identificação de danos e elaboração de laudos patológicos. Este tipo de trabalho também compete aos arquitetos e, diante da análise deste profissional, poderá enfatizar a importância da edificação relegando necessariamente à sua preservação. O presente artigo, elaborado como pesquisa acadêmica de iniciação científica, utilizou como objeto de estudo um conjunto de edificações minimalistas construídas na Região Metropolitana do Recife no auge da arquitetura modernista na década de 70, visando demonstrar o descaso com estas edificações ao mesmo tempo que se pretende incentivar a sua conservação. A partir de visitas in loco, fotografias e estudos de embasamento na temática de patologias das construções, foi elaborado um levantamento dos danos que possivelmente, comprometem sua estrutura e valores históricos. Os resultados identificaram que a edificação se encontra em estado de abandono, apesar de estar situada em uma área de preservação histórica. Ainda que algumas patologias são derivadas de falhas construtivas, em grande parte destas, a origem ocorre por ausência de manutenção preventiva e corretiva.

Palavras chave: Patologia; Manutenção; Edifícios Modernistas.

\section{ABSTRACT}

More and more modernist constructions built of reinforced concrete are fitting as historical. For this reason, it is necessary work in historic buildings preservation process which architects and urban planners are involved in damage identification stages and pathological reports. This type of job also competes to architects and, beyond point of view on this professional, can stress the building importance necessarily relegating to its preservation. The following article, elaborated as an academic resource, used as study object a group of minimalist buildings, installed in Metropolitan Region of Recife on peak of modernist architecture, in the seventh decade, aiming to demonstrate the disregard with these constructions, and in the meantime, intents to encourage their conservation. From local visits, photographs and based on constructions pathologies theme studies, it was prepared a damage lifting, which possibly, implicate itself structure and historical values. The results identified that the buildings are in state of abandon, besides it is located in a historical preservation area. Although some pathologies are derived from constructive failures, in most of all, their source happen from absence of prevented and corrected maintenance.

Keywords: Pathology; Maintenance; Modernists Buildings.

\section{INTRODUÇÃO}

Conforme aponta Silva; Oliveira e Naslavsky (2016), o conceito modernista na arquitetura começou a ser assentado no Brasil na década de 20 como projeto de uma nova sociedade propiciada pela industrialização, modernização e vida urbana. Com o passar dos anos, os arquitetos adaptaram as técnicas construtivas a que estavam acostumados a um novo 
método de projetar, utilizando um novo material: o concreto armado. Aos poucos o novo conceito se adequou às necessidades locais, e foram surgindo edificações consideradas ícones históricos desse marco arquitetônico.

Como toda obra, os edifícios são projetados para atender às necessidades de seus usuários e ao longo do tempo, surgem problemas patológicos decorrentes de falhas projetuais e construtivas ou mesmo da ausência de manutenção. O estudo de patologia das construções está voltado para análise das manifestações que se expressam visualmente ou não, e podem chegar a comprometer a estrutura.

Neste aspecto, foi elaborada uma análise dos danos apresentados em uma parte do conjunto das edificações de apoio do Parque dos Guararapes, localizado na Região Metropolitana do Recife, em que o projeto está inserido no partido das edificações modernistas brasileiras. Como também, o autor do projeto - o arquiteto Armando de Holanda Cavalcanti - é conhecido como um dos precursores dos estudos de adaptação do modernismo à arquitetura do nordeste brasileiro, adaptada aos trópicos mais quentes.

Apesar de atender às necessidades do projeto físico para o Parque, apenas as edificações destinadas às atividades de apoio administrativo usufruem da efetiva utilidade planejada em projeto. Segundo Tutikian e Pacheco (2013) que citam a NBR 15575 (ABNT, 2013), desempenho é o comportamento que uma edificação e seus sistemas apresentam durante o seu uso, estando diretamente relacionado com a manutenção realizada na edificação, o que influi diretamente na sua vida útil. Contudo, algumas edificações projetadas não apenas sofrem da ausência de manutenção, como são impossibilitadas de desenvolver a VUP (vida útil de projeto).

A proposta do presente trabalho é de destacar a obra, e como também, propor a participação dos arquitetos e urbanistas na etapa de análise patológica das edificações, antes de intervir ou restaurar. A compreensão dos valores históricos, e como também, os problemas que derivam das edificações é algo que os arquitetos estão habituados a deparar-se no contexto de arquitetura antiga - barroca, gótica, entre outras. Entretanto, quando a temática é voltada para o modernismo, o interesse para a participação de forma técnica nos processos de estudos patológicos ainda surge de forma tênue.

\section{DESENVOLVIMENTO}

\subsection{Anamnese do Edifício em Estudo}

\subsubsection{Breve Histórico}

Na década de 60, durante o regime militar no Brasil, a área dos Montes dos Guararapes - que engloba o morro do Telégrafo, o Monte dos Oitiseiros e o Outeiro dos Guararapes - no Distrito de Prazeres do município de Jaboatão, foi tombada com a importância de ser o local das batalhas dos Guararapes (1648 e 1649) e sendo considerada o "berço" do exército brasileiro. Logo após, esta região que era de responsabilidade da Ordem de São Bento, foi desapropriada e então, no ano de 1971 foi criado o Parque Histórico Nacional dos Guararapes. (HOLANDA, 1975)

Sabendo da importância de seu papel, o arquiteto Armando de Holanda Cavalcanti junto com sua equipe técnica elaborou em 1975 o Projeto Físico para o Parque. Sendo condicionados pelas estruturas já existentes - a Igreja de Nossa Senhora dos Prazeres e uma via principal -, os arquitetos elaboraram um projeto buscando um equilíbrio na distribuição dos equipamentos de acordo com sua função e respeitando seus limites.

$\mathrm{Na}$ proposta do projeto original, conforme pode-se conferir na Figura 1, estavam incluídas intervenções na infraestrutura do parque como abastecimento de água, energia, iluminação; a ampliação da delimitação do parque abrangendo incorporações no perímetro; transferência da população que na época, já estava crescendo na direção dos morros e, finalmente, a construção de edificações de apoio com o objetivo de atrair programas funcionais ao parque.

Contudo, não foi bem assim na execução do plano geral. Atualmente, apenas a região dos morros que é tombada pelo Instituto de Patrimônio Histórico e Artístico Nacional (IPHAN) ainda não recebeu instalações residenciais por completo. Por seguinte, há a possibilidade de regularização das moradias pois não há mais o controle sobre o crescimento e que não permite a relocação desta população. Sendo assim, do projeto físico, apenas algumas das edificações de apoio foram realizadas de acordo com o projeto de Holanda. Dentre os onze equipamentos programados, apenas o Pavilhão de acesso, junto com as edificações da área administrativa e militar, o mirante do morro dos 
Oitiseiros e as edificações destinadas às lanchonetes, próximas à igreja de Nossa Senhora dos Prazeres, foram construídas.

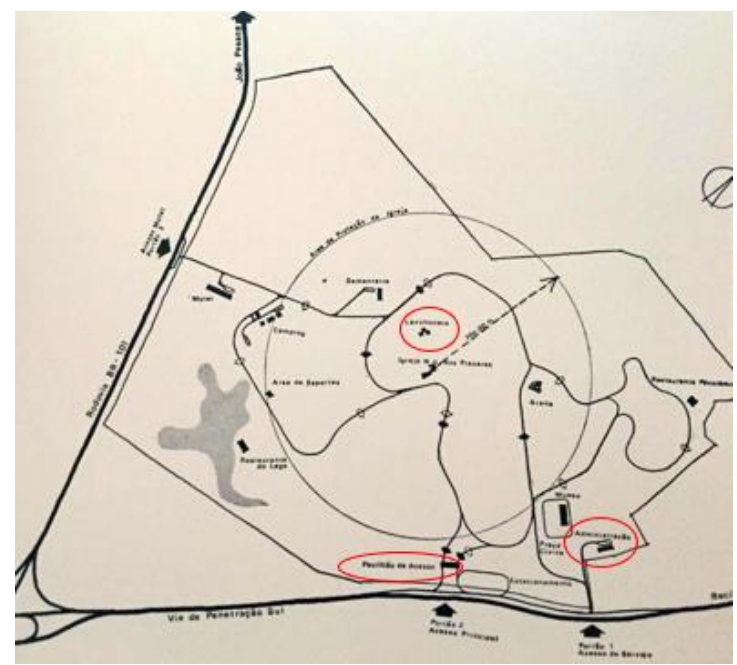

Figura 1: Mapa com implantação do Plano Geral do Projeto Físico do PHNG. Circuladas em vermelho, as edificações construídas. (Fonte: Livro Projeto Físico do PHNG, 1975).

Ao projetar as edificações de apoio do parque, os arquitetos foram bastante cautelosos, pois tinham o objetivo de manter uma reação destas com a Igreja e também, com a paisagem dos Guararapes. Apesar de não ter visibilidade geral de todas as edificações de um único ponto de observação, a equipe evitou usar características distintas para cada edificação. Armando de Holanda Cavalcanti tinha especialização em protótipos e, além de preocupar-se constantemente com uma arquitetura amena em sua inserção local, costumava praticar métodos construtivos que incluíssem possibilidades combinatórias simplificadas, racionalizadas e moduladas. (SILVA; OLIVEIRA; NASLAVSKY, 2016 , p. 144)

\subsubsection{Caracterização das edificações}

Utilizando como partido a unidade com repetição da mesma solução arquitetônica para cada edificação, foi criado um jogo combinatório de uma família de cascas de concreto formadas por triângulos de dupla curvatura, gerando cobertas padronizadas para as edificações de apoio do Parque dos Guararapes. Esta declaração evidencia fortemente a proposta utilizada pelo arquiteto sendo facilmente percebida na Figura 2.

De acordo com Armando de Holanda (1975, p. 43):

Estes triângulos, obtidos pelo corte de um paraboloide hiperbólico matriz ao longo de suas diagonais, geram famílias de casas de um, dois e quatro apoios, por suas posições relativas aos pilares. Foram adotadas as possibilidades combinatórias que melhor se adequavam a cada programa.
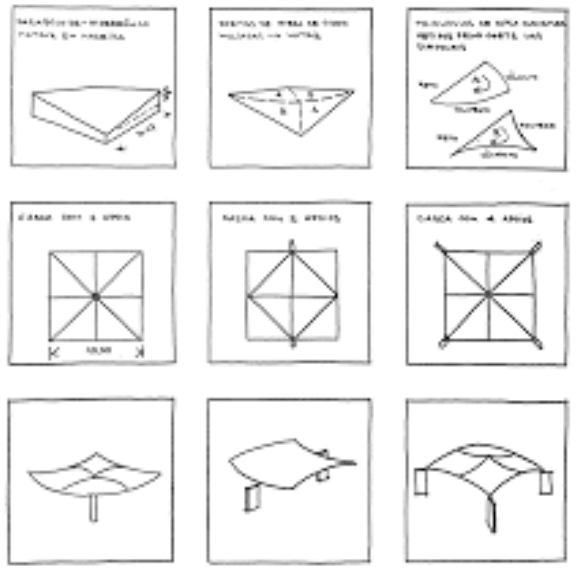

Figura 2: Estudo de formação das cascas. (Fonte: Livro Projeto Físico do PHNG, 1975.) 
No projeto do parque, Silva, Oliveira e Naslavsky (2016) ressaltam a relação com o livro cuja autoria também é do arquiteto, "Roteiro para Construir no Nordeste - Arquitetura como lugar ameno nos trópicos ensolarados" de 1976, por meio da criação de:

1. Sombras amplas: Com o prolongamento das cobertas que deixam áreas de circulação livres e protegidas;

2. Sombras abertas: Paredes internas e externas soltas da coberta, liberando espaço para ventilação cruzada e entrada de iluminação natural, diminuindo a necessidade de esquadrias e gerando economia;

3. Sombras amenas: Cobertas apoiadas em alguns pontos da estrutura, que em junção com sua forma - de execução permitida através da utilização de fibra de vidro - criam a possibilidade de grandes vãos e passam a impressão de leveza da estrutura.

Complementando o partido do arquiteto de simplificar e economizar na execução do projeto criando padrões racionalizados, Holanda tinha o objetivo de utilizar como acabamento a própria estrutura de concreto aparente em contraste com revestimentos cerâmicos para as paredes, gerando painéis - desenhados por Athos Bulcão. Bulcão, artista anteriormente conhecido por algumas parcerias bem renomadas durante o auge da arquitetura modernista no Brasil, e que produziu trabalhos resultantes da fusão decorativa e funcional, assim como previstas por Holanda nos painéis de azulejos do parque, projetados para proteger as fachadas das ações de intempéries - exceto no mirante do Morro dos Oitiseiros. (SILVA; OLIVEIRA; NASLAVSKY, 2016).

O trabalho nas edificações do parque foi resultado de uma parceria bem programada entre as técnicas de Armando de Holanda e o abstracionismo de Athos Bulcão. Característica fiel do artista, Bulcão criou um módulo de azulejo que, de acordo com a funcionalidade das edificações, tinham composições diversas - integração com o partido de Holanda em criar uma unidade para as edificações que evitassem a monotonia e repetição. Segundo Silva, Oliveira e Naslavsky (2016), a disposição dessas composições é correspondente a cada uma das três áreas onde as edificações construídas encontram-se:

1. O Pavilhão de Acesso do PHNG: Com visibilidade externa do Parque, consistia na coberta de um apoio e combinação aleatória dos azulejos (Figura 3);

2. Área Administrativa e Militar do PHNG: Consiste em uma coberta com quatro apoios e combinação ordenada de azulejos (Figura 4);

3. Lanchonetes do PHNG: Coberta de dois apoios com combinação de azulejos em ziguezague (Figura 5).

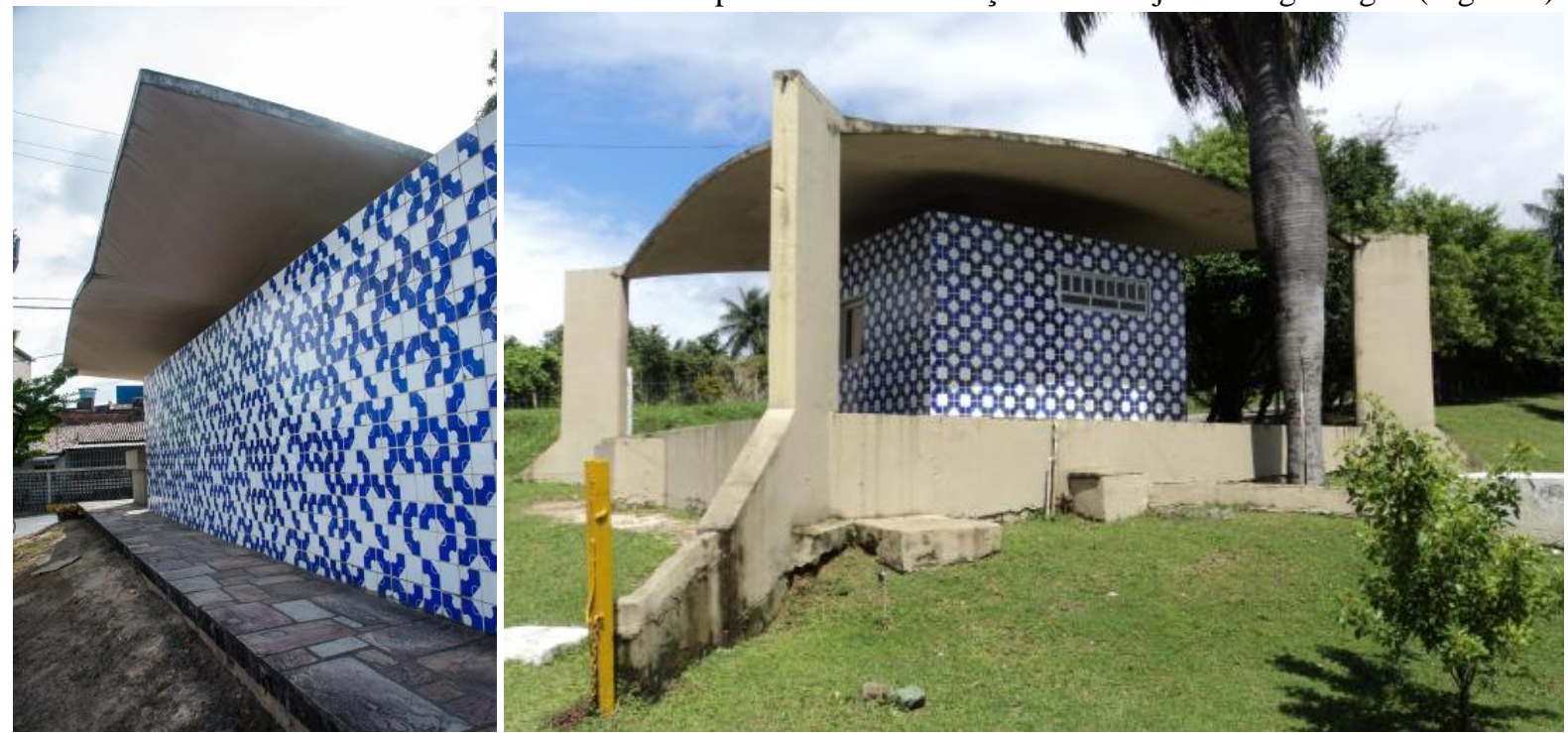

Figura 3, à esquerda: Pavilhão de Acesso do PHNG. Figura 4, à direita: Área administrativa e Militar. Fonte: Silva; Oliveira e Naslavsky (2016). 


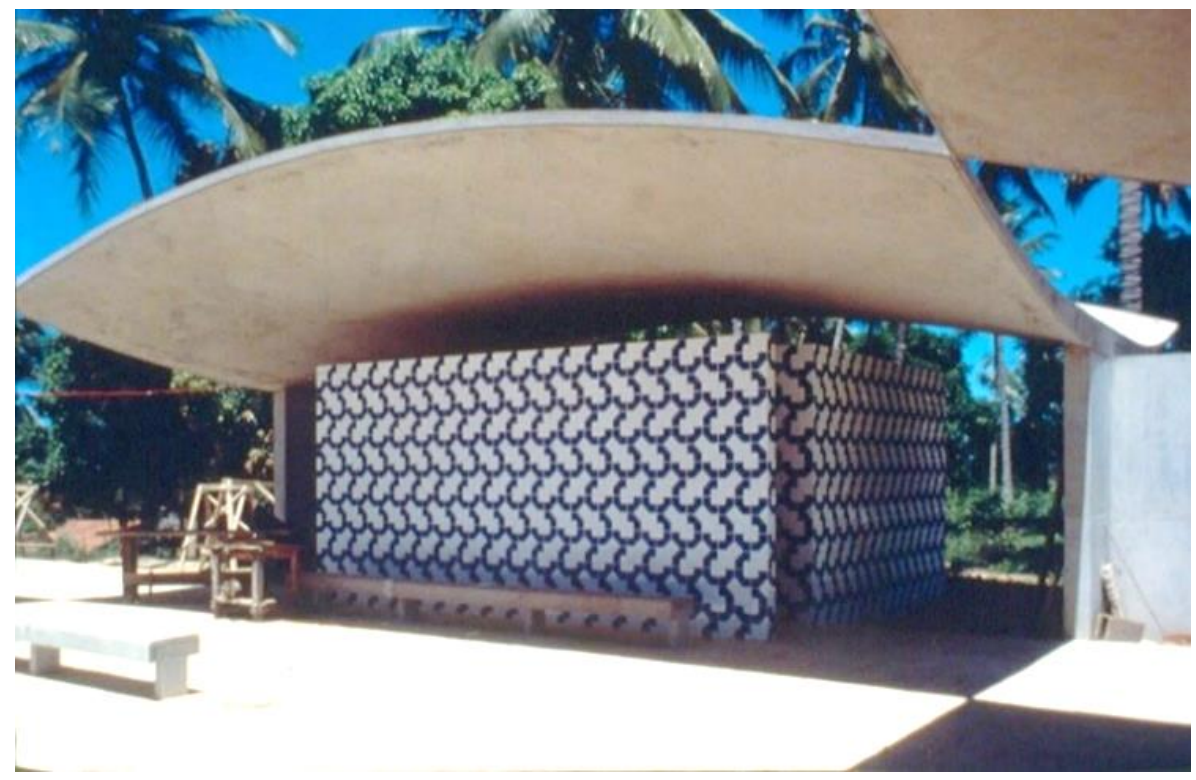

Figura 5: Uma das Lanchonetes do PHNG, quando inaugurada. Fonte: Tuca Reinés pela Página da Fundathos.

\subsection{Levantamento dos Danos}

Tomando como base o trabalho bem projetado de Holanda e Bulcão, a composição das lanchonetes foi selecionada como objeto de análise do presente trabalho. As edificações que atualmente encontram-se numa situação de abandono, permanecem sem uso e representam um foco de estudo patológico com problemas derivados de algumas falhas projetuais e de execução - intensificadas pela ausência de manutenção preventiva e corretiva.

Com base nos conhecimentos das técnicas construtivas e materiais utilizados, a princípio, se fez necessária uma análise visual generalizada das manifestações, identificando os problemas patológicos das edificações, para então, descobrir as possíveis causas e respectivos tratamentos. Para tanto, a partir de visitas in loco e elaboração de levantamento visual dos danos, foram encontrados cinco problemas patológicos mais frequentes nas três edificações que compõem o conjunto das lanchonetes do Parque, conforme apresentado na Figura 6.

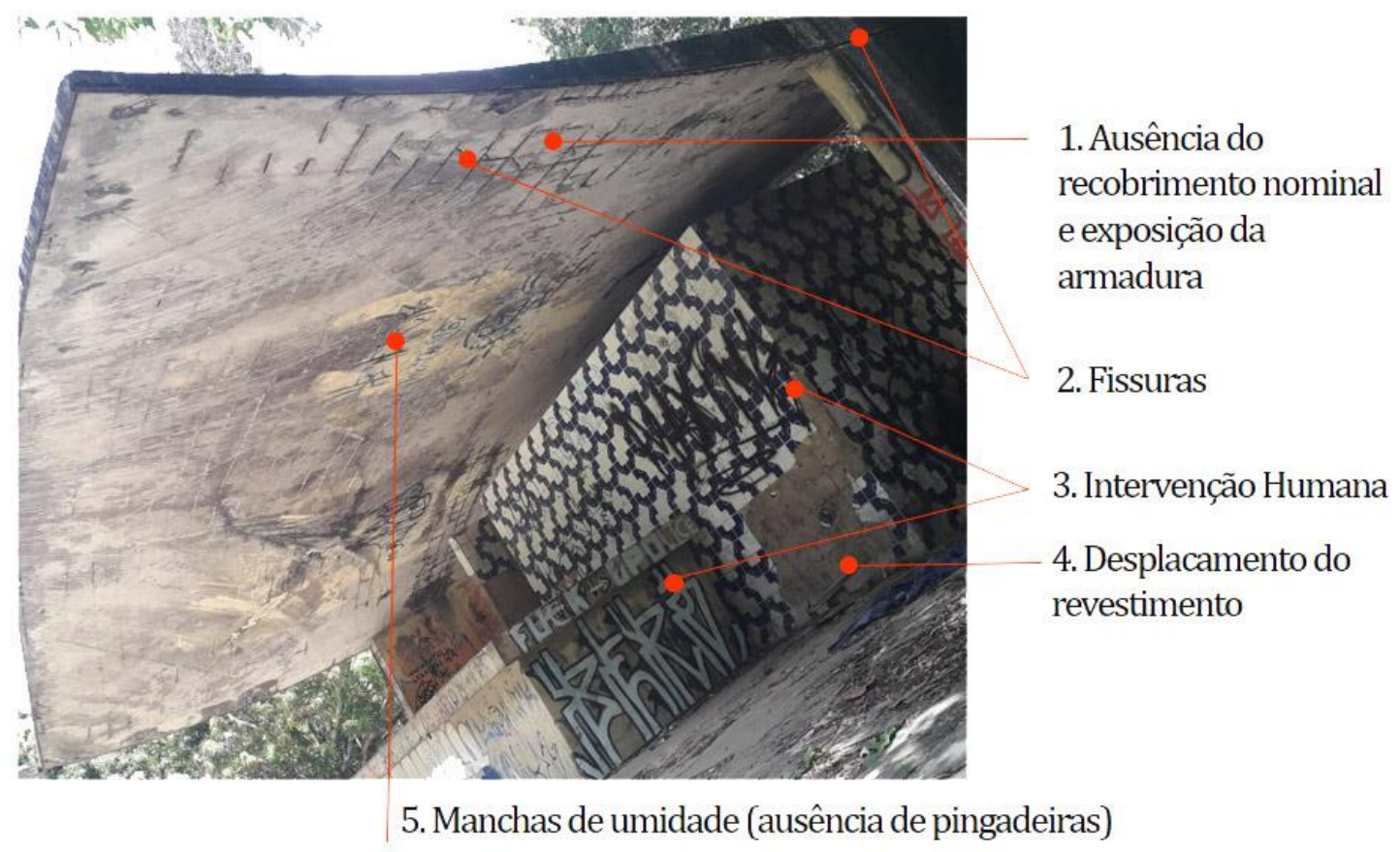

Figura 6: Os problemas patológicos encontrados nas lanchonetes do PHNG. (Fonte: Autores; 2019.) 
A identificação de todos os danos aparentes foi elaborada, em primeiro momento, com ênfase em apenas uma das lanchonetes, e logo após uma análise mais precisa, foi realizada a partir da confirmação de que os problemas estavam presentes nas três edificações que compõem o conjunto - que por sua vez, são semelhantes em formas e técnicas.

Segundo Tutikian e Pacheco (2013), o método de inspeção de um processo patológico deve determinar com rigor a origem, o mecanismo e os danos subsequentes, de forma que possa se concluir as recomendações mais eficazes. Devido ao porte e simplicidade da técnica construtiva das edificações, foi de certa forma prático o desenvolvimento da análise dos dados a partir da relação entre as origens das patologias e o método construtivo da obra, que tem como finalidade principal, descobrir as possíveis causas e prováveis tratamentos.

\subsection{Discussão dos Diagnósticos}

O projeto, por ser elaborado em meados da década de 70, não contava com o embasamento teórico de normas construtivas que regem as técnicas de construção atualmente. Apesar de não estarem situadas em uma zona de alta agressividade ambiental, o conjunto passou de ser projetado em uma zona mais natural para tornar-se urbano, a partir do avanço da urbanização no local do Monte dos Guararapes, como pode ser conferido na Figura 7. Segundo a NBR 6118 (ABNT, 2014), as edificações estão inseridas na zona de agressividade ambiental nível II (Urbana - moderada) e devido à ampliação da ocupação irregular de moradias, reduzindo a área original do Parque de 224 hectares para aproximadamente 80 hectares - o que acarreta na restrição das condições de uso do parque e diminui os recursos naturais (MONTENEGRO, 2014).

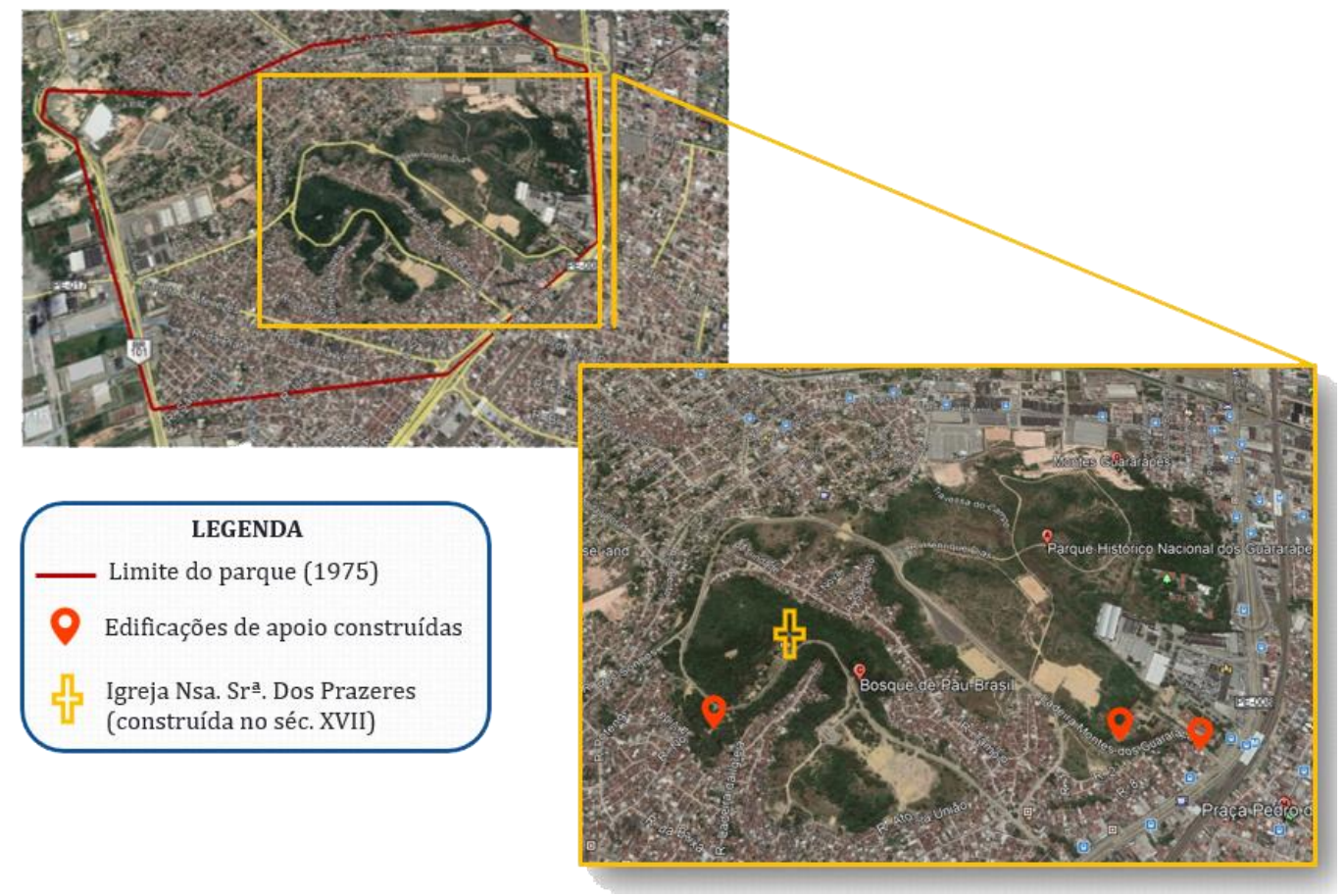

Figura 7: Localização do PHNG, edificações de apoio que foram construídas e da Igreja Nsa. $\mathrm{Sr}^{\mathrm{a}}$ dos Prazeres. Fonte: Imagem de Satélite Google Earth (2018).

O problema patológico que mais sobressai visualmente nas edificações é o da exposição das armaduras (Figura 8). Ao analisar a espessura das lajes e a utilização da forma construtiva com dupla curvatura, é possível chegar à conclusão que os elementos encontram-se com ausência de recobrimento nominal em vários trechos da edificação. Essas lajes, que tinham como objetivo estético transmitir a sensação de leveza sobre a estrutura de concreto aparente, foram moldadas com uma espessura relativamente curta, e provavelmente, deixou a armadura muito próxima da face externa do elemento. Conforme pode ser observado nas Figuras 9 e 10, onde também pode se constatar que a exposição das armaduras é predominante nos trechos em que a laje tem o comportamento de curvatura para baixo. 


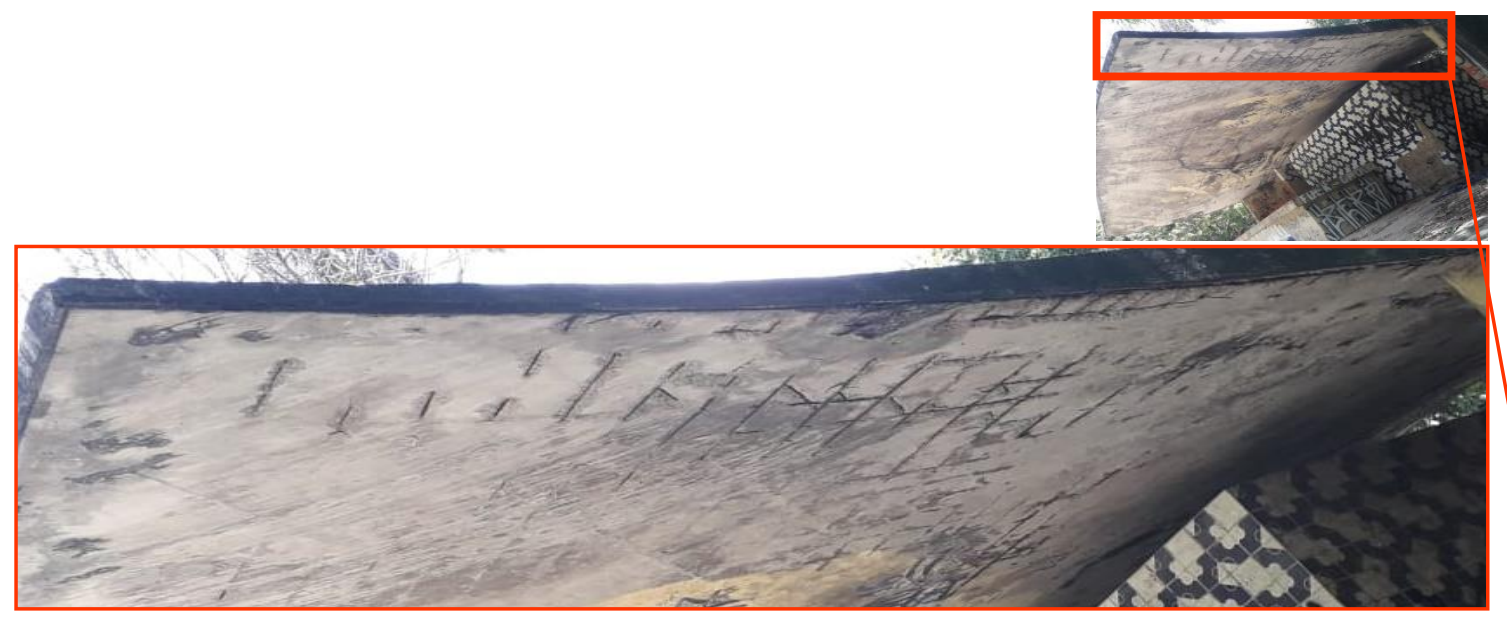

Figura 8: Condições de exposição da armadura da laje nas lanchonetes do parque. (Fonte: Autores; 2019)
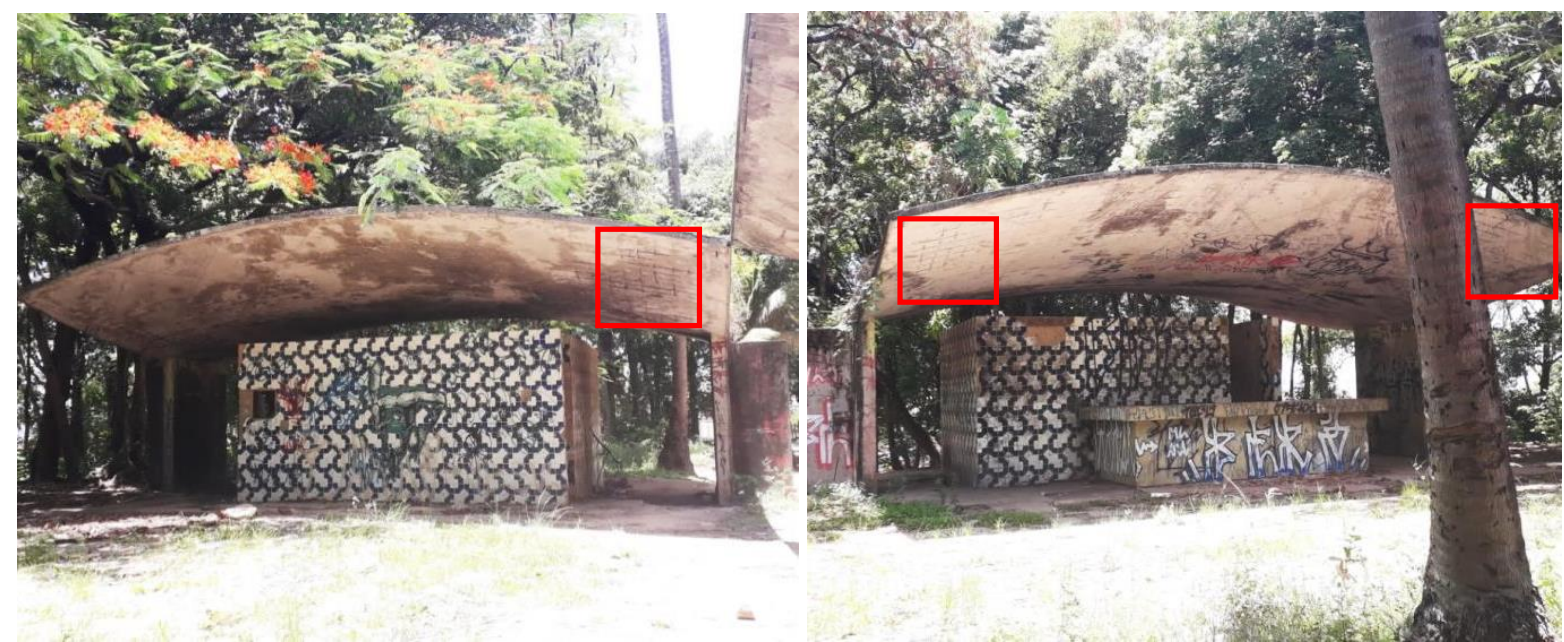

Figuras 9 e 10: Exposição da malha de aço das lajes nos trechos em que a curvatura do elemento é côncava. (Fonte:

Autores; 2019)

Essa exposição da armadura em contraste com a urbanização predominante do local, gera grande possibilidade de corrosão por carbonatação - provocada pela ação do $\mathrm{CO}_{2}$ presente na atmosfera poluída que, por sua vez, promove a desalcalinização do concreto e consequente despassivação das armaduras. Muito embora exista uma alta probabilidade do diagnóstico positivo para corrosão por carbonatação, antes de cogitar algum tipo de tratamento para essa questão, é necessário que primordialmente sejam realizados ensaios colorimétricos (asperção do $\mathrm{AgNO}_{3}$ e fenolftaleína) para descobrir qual tipo de corrosão - por carbonatação ou cloreto (visto que esta possibilidade também deve ser considerada em função da alta probabilidade de contaminação por cloretos através do uso de materiais infectados) - e o avanço que a mesma atingiu. Dependendo da situação, seria de suma importância a construção de um recapeamento da estrutura da laje, ampliando a espessura desta e protegendo a estrutura de deteriorações futuras.

Segundo relatos coletados sobre o estudo de viabilidade do partido arquitetônico das edificações, o autor do projeto previa a utilização de fibra de vidro na composição do concreto com a finalidade de aumentar a consistência do concreto e melhorar a trabalhabilidade do material na composição que desejava realizar. Há alguns estudos recentes que sugerem interferências que esta técnica pode causar ao longo do tempo, e segundo Bonifácio e Godinho (2014) é provável a existência de uma relação com o aparecimento das fissuras - segundo a Figura 11.

Devido à ausência de vigas para transmitir os esforços das lajes aos pilares de apoio, o processo de dilatação térmica pode ser outra causa das fissuras nas edificações. Não é possível identificar na ligação laje - pilar a existência de juntas de dilatação que possa facilitar que os elementos façam sua movimentação estrutural natural, como resinas ou outros materiais semelhantes (vínculo, rótula, elemento de transição, entre outros) usualmente aplicados entre as peças estruturais. 

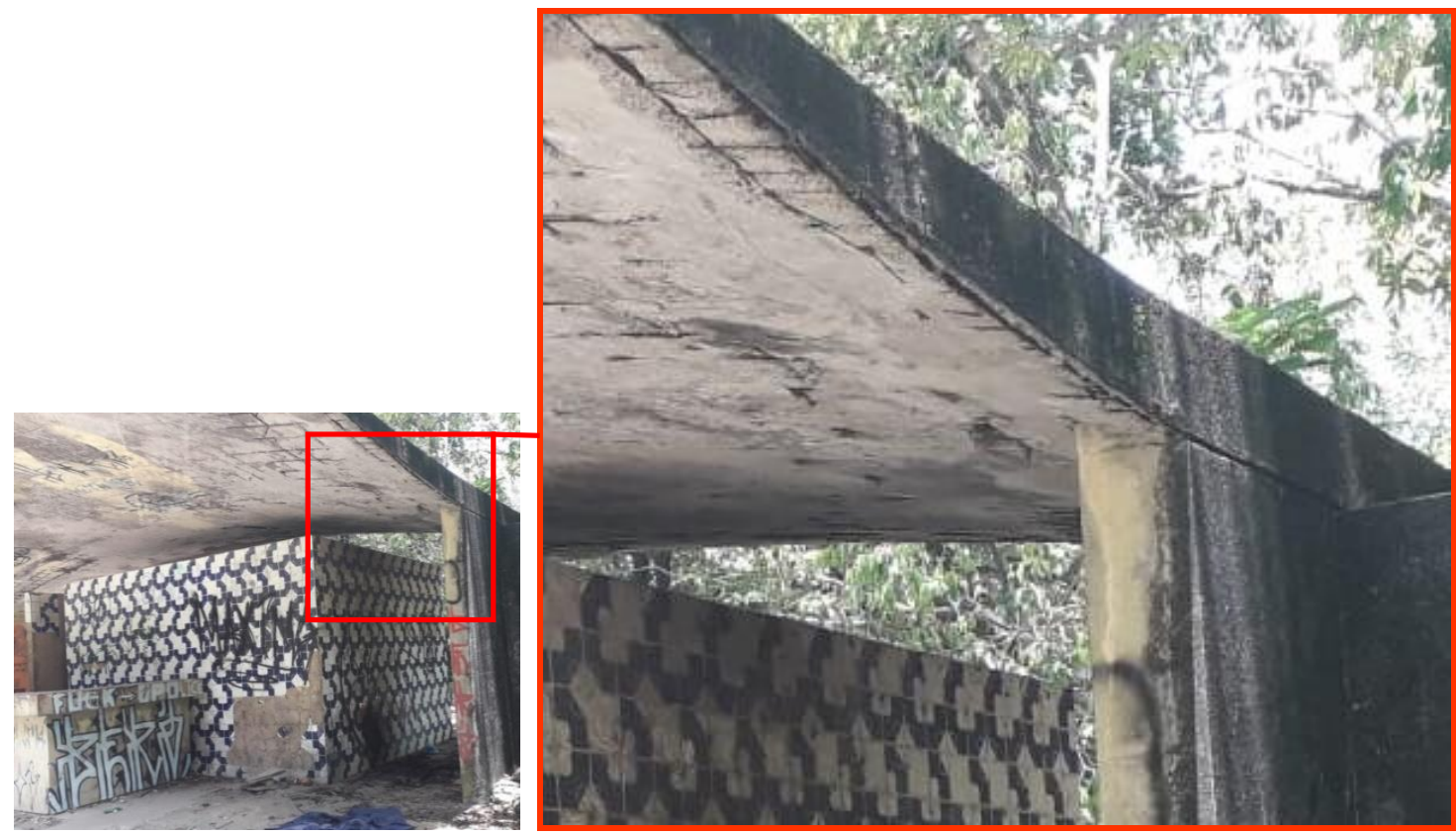

Figura 11: Ligação da laje e pilar de apoio e fissuras situadas na laje de uma das lanchonetes. (Fonte: Autores; 2019)

Outra anomalia predominante nas edificações são as manchas no concreto ocasionadas por umidade. Ao escolher as cascas de dupla curvatura em concreto aparente como solução de coberta para o conjunto - a fim de evitar utilizar calhas que pudessem obstruir devido à localização abaixo de árvores de grande porte (Figura 12) - não foi previsto em projeto elementos de drenagem pluvial, como drenos ou pingadeiras. O acúmulo de água em contato direto com o concreto pode causar manchas como as demonstradas na Figura 13 e, consequentemente, permear entre os materiais componentes. O processo de infiltração na estrutura acontece, normalmente, por meio da percolação através das fissuras existentes, e que possivelmente causa a lixiviação reduzindo a alcalinidade do concreto e promovendo o aparecimento das eflorescências - manchas de precipitados brancos $\left(\mathrm{CaCO}_{3}\right)$ e geralmente insolúveis, que auxiliam no desenvolvimento dos processos corrosivos.
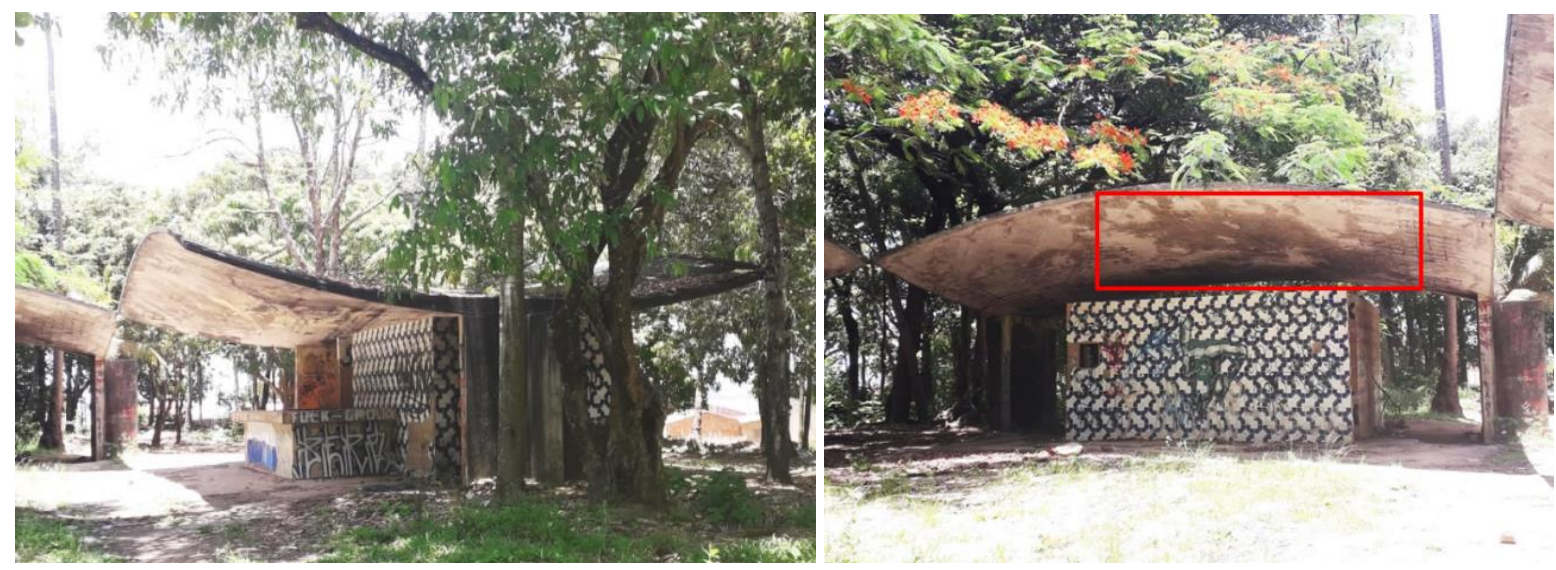

Figura 12: Edificação sob árvores de grande porte. (Fonte: Autores; 2019); Figura 13: Manchas por umidade decorrentes do escoamento de águas pluviais pela coberta de concreto. (Fonte: Autores; 2019)

O revestimento projetado cautelosamente para as edificações sofreu desplacamento em algumas partes, como é possível conferir na Figura 14. Este problema pode estar relacionado a diversas causas apresentadas na etapa de execução ou até mesmo, na fabricação de placas com teor de absorção mais alto que o ideal. Contudo, como o revestimento utilizado tem uma mesma origem de fabricação para as outras edificações do parque e o único que sofre de desplacamento é o das lanchonetes, é possível chegar à conclusão que a causa dessa patologia está relacionada à falta de uso e, consequentemente, de manutenção. Assim como também é possível verificar as ações de intervenção humana como a grafitagem e pinturas sobre o acabamento das edificações, que atenuam a exposição das edificações à agentes químicos e, de certa forma, à marginalização. 

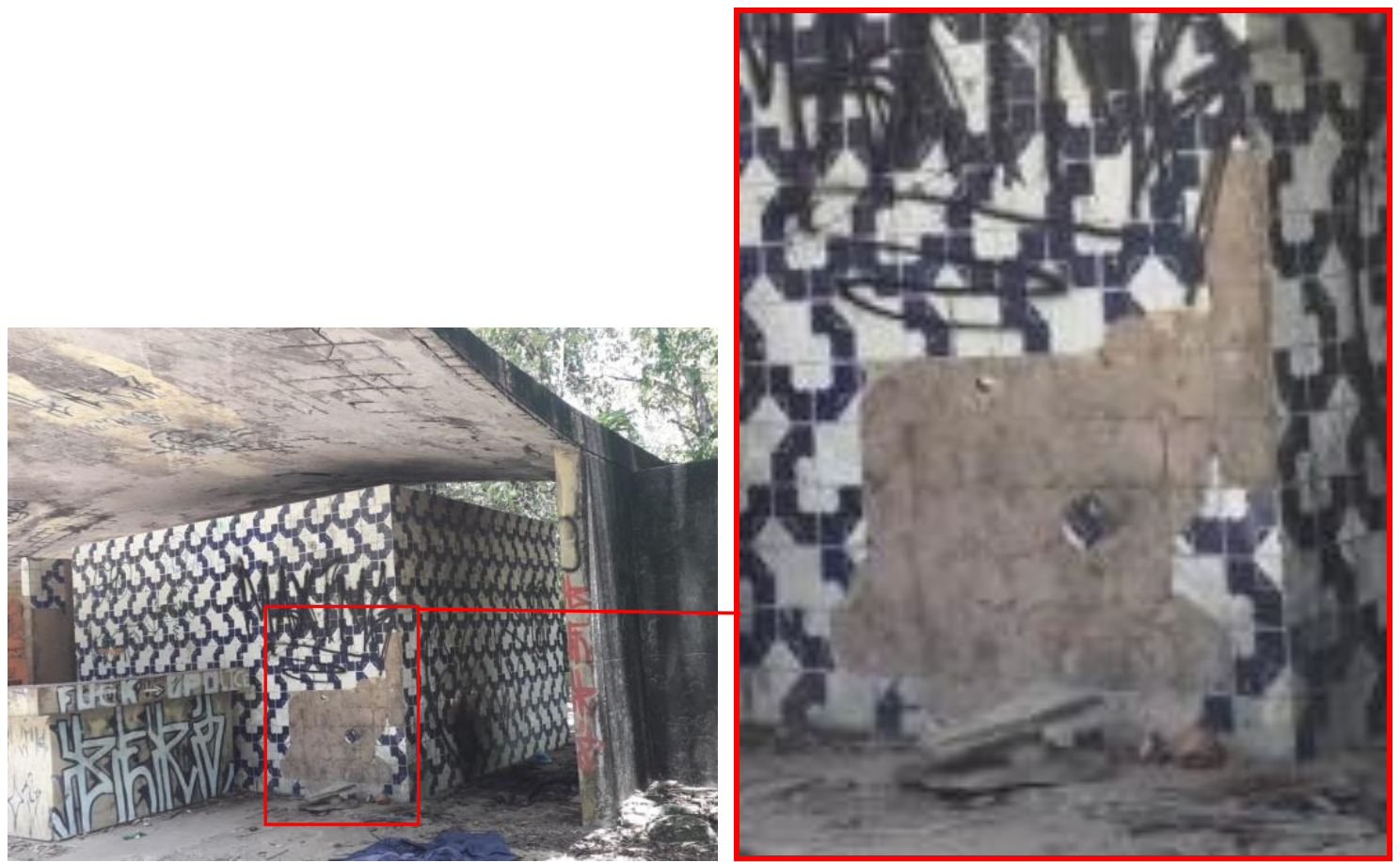

Figura 14: Desplacamento do revestimento na parede de uma das lanchonetes. (Fonte: Autores; 2019)

Contudo, de acordo com algumas teorias no âmbito de restauro, fica relativamente em aberto a questão de recuperação para os problemas estéticos das edificações - afinal, algumas patologias são decorrentes do abandono presente na história da obra. A defesa da ideologia quanto às possíveis soluções para este problema ainda é muito pessoal, e como os pequenos prédios do projeto não são tombados como patrimônio histórico, não cabe às autoridades públicas a questão de cuidados e possíveis tratamentos a realizar, facilitando assim seu abandono e deterioração natural.

A seguir apresenta-se um quadro resumo que pode contribuir para manutenção do edifício em análise.

\begin{tabular}{|c|c|c|c|c|}
\hline & $\begin{array}{l}\text { PROBLEMA } \\
\text { PATOLÓGICO }\end{array}$ & RECOMENDAÇÕES & CAUSA/ORIGEM & TRATAMENTO \\
\hline 1. & $\begin{array}{l}\text { Corrosão das armaduras } \\
\text { da laje (casca) }\end{array}$ & $\begin{array}{lr}\text { Realizar } & \text { ensaios } \\
\text { colorimétricos } & \text { de } \\
\text { carbonatação } & \text { com } \\
\text { indicadores químicos e } \\
\text { asperção de AgNO3 } \\
\text { para identificação do } \\
\text { tipo de corrosão. }\end{array}$ & $\begin{array}{l}\text { Ausência de } \\
\text { recobrimento } \\
\text { nominal. }\end{array}$ & $\begin{array}{l}\text { - Reparo das armaduras danificadas } \\
\text { (lixamento, substituição e aplicação de } \\
\text { produto anti-oxidante); } \\
\text { - Executar camada em concreto com nova } \\
\text { espessura de cobrimento nominal. }\end{array}$ \\
\hline 2. & Fissuração & $\begin{array}{lr}\text { Fazer monitoramento } \\
\text { das fissuras para } \\
\text { identificação } r \\
\text { ocorrência desta de } \\
\text { forma ativa ou passiva. }\end{array}$ & $\begin{array}{ll}\text { Ausência } & \text { de } \\
\text { elementos } & \text { de } \\
\text { dilatação térmica. }\end{array}$ & $\begin{array}{l}\text { Realizar fechamento das fissuras com } \\
\text { material plástico (em caso de fissuras } \\
\text { ativas) ou material rígido (em caso de } \\
\text { fissuras passivas). }\end{array}$ \\
\hline 3. e 4 . & $\begin{array}{l}\text { Desplacamento } \quad \mathrm{e} \\
\text { deterioração } \\
\text { revestimento/Intervenção } \\
\text { humana }\end{array}$ & & $\begin{array}{lr}\text { Ausência } & \text { de } \\
\text { manutenção } & \text { e } \\
\text { abandono } & \text { da } \\
\text { estrutura. } & \end{array}$ & $\begin{array}{l}\text { Promover a limpeza das peças com } \\
\text { material não abrasivo e, a depender da } \\
\text { abordagem do restauro do painel, } \\
\text { encomendar novas peças semelhantes às } \\
\text { de assinatura de Athos Bulcão. }\end{array}$ \\
\hline 5. & $\begin{array}{l}\text { Manchas por umidade } \\
\text { (infiltração) }\end{array}$ & & $\begin{array}{lr}- \text { Fissuras na laje } & \text { e } \\
\text { perda } & \text { do } \\
\text { desempenho } & \text { da } \\
\text { camada } & \\
\text { impermeabilizante; } \\
\text { - Ausência } & \text { de }\end{array}$ & $\begin{array}{l}\text { - Realizar fechamento das fissuras e } \\
\text { executar nova camada de } \\
\text { impermeabilização; } \\
\text { - Nos bordos das lajes executar } \\
\text { pingadeiras conforme Figura } 15 .\end{array}$ \\
\hline
\end{tabular}




\begin{tabular}{|l|l|l|l|}
\hline & & $\begin{array}{l}\text { pingadeiras e/ou } \\
\text { outros elementos de } \\
\text { drenagem pluvial. }\end{array}$ & \\
& & $\begin{array}{c}\text { Figura 15: Detalhe de rufo pingadeira na } \\
\text { borda de lajes. }\end{array}$ \\
\hline
\end{tabular}

\section{CONSIDERAÇÕES FINAIS}

Apesar de alguns problemas apresentados nas edificações de apoio do Parque dos Guararapes serem decorrentes de falhas construtivas, é considerável que o projeto foi elaborado em uma época em que ainda não se discutia no Brasil sobre a durabilidade e manutenção de estruturas de concreto. O projeto das edificações de apoio do parque claramente cumpriu às necessidades de planejamento funcional com unidade e identidade garantindo simplicidade e economia de execução - o que era característica fundamental de grandes obras da arquitetura modernista.

Contudo, os projetos arquitetônicos devem ser previstos levando em consideração o processo de manutenção que a edificação deverá passar ao longo dos anos. Ao atender o uso a que será destinado, os projetos arquitetônicos devem apresentar funcionalidade e identidade, com abertura para que a manutenção periódica possa ser realizada sem interferir em nenhum dos seguintes aspectos. No caso das edificações do Parque, a manutenção não foi realizada pois as edificações foram indevidamente inutilizadas, apresentando patologias que caracterizam sinais de abandono.

É importante ressaltar também, a participação dos arquitetos e urbanistas no processo de estudos patológicos em edificações de grande relevância histórica, pois a profissão está inserida no mercado com a habilidade de compreender e comprometer-se em preservar os valores que guardam essas obras de autoria significativa. Apesar de não ter o reconhecimento merecido, as edificações que marcaram a parceria do arquiteto Armando de Holanda Cavalcanti e o artista Athos Bulcão guardam grande valor para a arquitetura moderna dos trópicos quentes, assim como muitas outras que provavelmente devem existir às sombras desta infeliz questão.

Conhecer sobre a importância da edificação antes de pontuar os problemas patológicos que aparecem é de certa forma, primordial - reforçando a relevância do ponto de vista da profissão dos arquitetos e urbanistas neste aspecto. Contudo, preservar é um dilema na sociedade brasileira contemporânea, mas o ato de intervir indevidamente ainda é bastante comum nos parâmetros urbanísticos - onde a população se apropria ou até contribui na deterioração de determinadas edificações de grande relevância histórica.

\section{REFERÊNCIAS}

Associação Brasileira de Normas Técnicas. NBR 6118: Projeto de Estruturas de Concreto - Procedimento. Rio de Janeiro, 2014.

Bonifácio, J. S., Godinho, D. Estudos do efeito das fibras de vidro e polipropileno nas propriedades mecânicas do concreto. SC, 2014. Dissertação para conclusão no curso de Engenharia Civil - UNESC.

Cichinelli, G. Patologias cerâmicas: por que ocorrem os desplacamento e trincas em edificações revestidas com cerâmicas e quais as recomendações dos especialistas para evitar problemas. Revista Téchne: a revista do Engenheiro Civil, n 116, p. 44-50, nov. 2006.

Montenegro, G. A. A.; A Gestão do Parque Histórico Nacional dos Guararapes: análise e proposições. PE, 2014. Dissertação apresentada no Mestrado Profissional em Gestão Pública para o Desenvolvimento do Nordeste - UFPE.

Parque Histórico Nacional dos Guararapes: projeto físico. Recife, UFPE, 1975. 64 p. 
Pozzani, R., Pombal, D., Garcia, A., Malvezi, L.F, José, C. Restauro: Rua Florêncio Abreu. SP, 2011. Centro Universitário FIAM FAAM - Faculdades Integradas Alcântara Machado e Faculdade de Artes Alcântara Machado, SP.

Roteiro para Construir no Nordeste: arquitetura como lugar ameno nos trópicos ensolarados. Recife: Ed. Universitária da UFPE, Mestrado em Desenvolvimento Urbano, 1976. 48 p.

Silva, C. C., Oliveira, A. F., e Naslavsky, G. Entre o Concreto e o Abstrato: As Obras de Armando de Holanda Cavalcanti com Athos Bulcão. PE, 2016. Cadernos de Pós Graduação em Arquitetura e Urbanismo - Universidade Federal de Pernambuco.

Siqueira, G. H. M.; Concreto Armado: Uma análise de patologia e reparo. Página da UNILESTE. Disponível em: <https://www.unileste.edu.br/noticia/2813/concreto-armado-uma-analise-de-patologia-e-reparo> Acesso em: 25 de Julho de 2019.

Tutikian, b.; Pacheco, M. Boletín Técnico - Inspección, Diagnóstico y Prognóstico em la Construcción Civil. Merida - Méxino, 2013. 